\title{
$522 y$
}

Ein Fall von multiplen Darmsteinen beim Menschen.

Von

Carl Th. Mörner in Upsala.

(Der Redaction zugegangen am 14. December 1896.)

Bei den pflanzenfiressenden Thieren, besoncers den Hirsch- und Pferdegattungen, kommen Darmsteine nicht gar $\mathrm{zu}$ selten vor und erreichen mitunter eine fast enorme Grösse. Anders stellt sich das Vorkommen bei den $M \in n$ schen. Darmsteine sind bei ihnen überhaupt eine ziem lich seltene Erscheinung und besonders ist dies der Fall, wenn man unter Darmsteinen im engsten Sinne des Wortes nicht die im Processus vermiformis gebildeten Concremente versteht, die meist von unbedeutender Grösse besonderen an atomischen Umständen ihre Entstehung verdanken. Wenn man den Begriff so einschränkt, sind die eigentlichen Darmsteine des Menschen als Seltenheiten anzusehen, wenn sie zuweilen in ausgeleerten Fäcalmassen oder bei Obductioren angetroffen werden.

Ein diesbezüglicher Fall ist neulich zu meiner Kenntniss gelangt. Mit ausgezeichneter Liebenswürdigkeit hat mir ler Beobachter, Dr. med. Rudberg, Lazaretharzt in Söderhann, Schweden, die 5 Steine, die er noch besass, nachdem mehrere andere (etwa 1 Dutzend) vorhandene Darmsteine bei der 
Operation weggeworfen worden waren, zugestellt. Aus seinen eigenhändigen Mittkeilungen ergeben sich die wichtigsten casuistischen Data.

«Der Fall bezieht sich auf einen jungen (23jährigen) Bauern. Seine Eltern behaupten, dass seit dem 9. Lebensjahre keine natürliche Darmentleerung stattgefunden hat, sondern in langen und immer längeren Zwischenzeiten nothdürftig mit künstlichen Mitteln hat hervorgerufen werden müssen. Schmerzen bei der Defäcation sollen den nächsten Anlass gegeben haben, dass der Kranke sich der Ausleerung zu enthalten genöthigt sah. Bei der Ankunft im Krankenhaus wurde angegeben, dass eine fast unglaubliche Zeit nach der letzten Ausleerung verflossen sei; weil nämlich die Aftergegend selbst bei der leisesten Berührung intensiv schmerze, habe sich der Kranke irgend einer Behandlung zu unterziehen geweigert. Der Bauch war ansehnlich aufgetrieben. Wenn man die Aftergegend, die merkbar nach aussen buchtete, zu betasten versuchte, schrie der Kranke laut auf und wollte davon laufen. Endlich überredete man ihn, sich chloroformiren $\mathrm{zu}$ lassen. Beträchtliche Quantitäten eines schwarzen Gemenges, das vielmehr dumpfiger, zusammengebrannter Torfmoorerde als Fäces ähnlich sah, wurden aus dem Dar'm herausgebracht. Darin eingebettet fanden sich mehrere sämmtlich facettirte Fäcalsteine derselben Art, wie die beigefügten; weiter wurden auch Uebergangsformen aus allen Entwickelungsstadien, von halbfesten bis $\mathrm{zu}$ festen, aber zerquetschbaren Bildungen von ganz derselben äusseren Form, wie der der eigentlichen Steine, angetroffen. Der allgemeine Zustand des Kranken war bemerkenswerth gut und hat sich während des Aufenthaltes im Lazareth noch weiter gebessert».

Sämmtliche Steine, die zu meiner Disposition gestellt wurden, waren unregelmässig facettirt mit $\mathbf{4 - 5}$ ziemlich ebenen, durch abgestutzte Kanten von einander getrennten Flächen. Die Oberfläche war glatt und hart, grauweiss mit dunkleren und helleren Schattirungen, was sie von Wasser geschliffenen Kieseln sehr äbnlich machte. Das Gewicht betrug resp.: 1) 7,5, 2) 8,3 , 3) $8,3,4) 10,8$ und 5) 12,2 gr. Um 
die innere Struktur zu erforschen, wurde ein jeder Stein derart durchgesägt, dass zwei Stücke von etwa derselben Grösse erhalten wurden; an sämmtlichen Steinen trat eine scharfe Grenze zwischen einer äusseren "Schale» und einem inneren «Ker $\mathrm{n}$ » hervor. Was den letzteren anbelangt, bestand dieser bei Nr. 3 und 5 aus einem gut erhaltenen Pflaumensteine; um welchen die feste Schale sich unmittelbar anschmiegte. In den übrigen Steinen bestand der Kern aus einem braunschwarzen, trockenen, farblose Krystalle einschliessenden Gemenge. Die Cohärenz ist nicht gross, so dass der Stoff ohne Schwierigkeit mit einem kleinen Messer ausgekratzt werden kann, wobei er als ein trockenes, aus gröberen und feineren Partikelchen zusammengesetztes, bräunliches Pulver erhalten wird. Nach dem Auskratzen bleibt eine scharf begrenzte Höhle, die den Platz des "Kerns» anzeigt, zurück. Die kleinen Krystalle bestehen aus Ammonium-Magnesiumphosphat, der braune Stoff dagegen hat sich, nachdem dureh Auskochen mit Essigsäure anorganische Verbindungen entfernt worden waren, hauptsächlich als cellulosehaltige Pflanzenreste verschiedener Art erwiesen, wie die Umstände bei Verbrennung und bei mikroskopischer Untersuchung übereinstimmend ergeben. Die Schale ist in den verschiedenen Steinen von wechselnder Dicke, im Uebrigen dagegen völlig gleichartig. Sie ist hart. und schwer, von einer homogenen und besonders dichten Struktur und von hellgrauer Farbe. Weil diese Schale, was Gewicht und auch Volumen anbelangt, die Hauptmasse der Steine bildet, ist sie einer genaueren chemischen Prüfung unterzogen worden, wobei die Schale des Steines Nr. 1) Gewicht etwa 6,0 gr.) zum feinsten Pulver zerrieben, als Material gedient hat.

Nachdem durch qualitative Reactionen Magnesium, Calcium, Ammonium, Natrium, Phosphorsäure, Kohlensäure, Fettsäure, Neutralfett, in Aether und Essigsäure unlöslich er organischer Rest (Cellulose und humusartiger Stoff) und Spuren von in den erwähnten Lösungsmitteln löslichen organischen Substanz constatirt, während Schwefelsäure, Chlorwasserstoff, Oxalsäure, Gallenfarbstoff und Cholesterin ausgeschlossen wor- 
den waren, gab die quantitative Analyse folgende Zusammensetzung an :

$$
\begin{aligned}
& \text { Ammonium-Magnesiumphosphat }\left(\mathrm{NH}_{4} \mathrm{MgPO}_{4}+6 \mathrm{H}_{2} \mathrm{O}\right) \quad 82,23 \% \text {. } \\
& \text { Calciumphosphat }\left(\mathrm{Ca}_{3}\left(\mathrm{PO}_{4}\right)_{2}\right) \text {. . . . . . . . . 5,24 » } \\
& \text { Magnesiumphosphat }\left(\mathrm{Mg}_{3}\left(\mathrm{PO}_{4}\right)_{2}\right) \text {. . . . . . . 1,64 » } \\
& \text { Calciumcarbonat . . . . . . . . . . . . . . 1,61 " } \\
& \text { Fettsaures Calcium . . . . . . . . . . . . . 0,75 " } \\
& \text { Neutralfett . . . . . . . . . . . . . . . 0,20" } \\
& \text { Unlösliches, organ. Substanz . . . . . . . . . . 1,90» } \\
& \text { Wasser, Spuren von löslicher organ. Substanz, Na- } \\
& \text { trium etc. . . . . . . . . . . . . . . } \frac{6,43 » 1)}{100,00 \% \text {. }}
\end{aligned}
$$

Die Hauptmasse des Steines besteht also grösstentheils aus anorganischen Verbindungen. Was im vorliegenden Falle Beachtung verdienen dürfte, ist theils die multiple Anhäufung der Steine, theils die Art des «Kerns», indem dieser in zwei Fällen von fünf aus gut erhaltenen Pflaumensteinen bestand, was die Annahme zu stützen scheint, dass ein Herunterschlucken von derartigen Gegenständen, möglicherweise den ersten Anlass einer Steinbildung im Darme geben kann, und also mit einer gewissen Gefahr für die Gesundheit und das Leben verbunden ist.

1) Diese Zahl ist als Differenz erhalten. Directe Bestimmung des Wassers durch Trocknen bei $+100^{\circ}$ G. war hier nicht zu benutzen, weil das Ammonium-Magnesiumphosphat schon bei dieser Temperatur sein Krystallwasser theilweise verliert. 